\title{
Effect of tiotropium/olodaterol on sedentary and active time in patients with COPD: post hoc analysis of the VESUTO ${ }^{\circledR}$ study
}

This article was published in the following Dove Press journal:

International Journal of Chronic Obstructive Pulmonary Disease

\author{
Yoshiaki Minakata (D) \\ Takashi Motegi ${ }^{2}$ \\ Jun Ueki ${ }^{3}$ \\ Yasuhiro Gon $\mathbb{D}^{4}$ \\ Shuhei Nakamura ${ }^{5}$ \\ Tatsuhiko Anzai $\mathbb{D i D}^{6}$ \\ Kazuto Hirata ${ }^{7}$ \\ Masakazu Ichinose ${ }^{8}$ \\ 'Department of Respiratory Medicine, \\ National Hospital Organization \\ Wakayama Hospital, Wakayama, Japan; \\ ${ }^{2}$ Department of Pulmonary Medicine and \\ Oncology, Graduate School of Medicine, \\ Nippon Medical School, Tokyo, Japan; \\ ${ }^{3}$ Clinical Research Unit of Respiratory \\ Pathophysiology, Juntendo University \\ Graduate School of Health Care and \\ Nursing, Chiba, Japan; ${ }^{4}$ Division of \\ Respiratory Medicine, Department of \\ Internal Medicine, Nihon University \\ School of Medicine, Tokyo, Japan; \\ ${ }^{5}$ Medical Division, Nippon Boehringer \\ Ingelheim Co. Ltd., Tokyo, Japan; ${ }^{6}$ Clinical \\ Information Division Data Science \\ Center, Statistics Analysis Department I, \\ EPS Corporation, Tokyo, Japan; \\ ${ }^{7}$ Department of Respiratory Medicine, \\ Graduate School of Medicine, Osaka City \\ University, Osaka, Japan; ${ }^{8}$ Department of \\ Respiratory Medicine, Tohoku University \\ Graduate School of Medicine, Sendai, \\ Japan
}

Correspondence: Yoshiaki Minakata Department of Respiratory Medicine, National Hospital Organization Wakayama Hospital, I I8I Wada, Mihama-cho, Hidakagun, Wakayama 644-0044, Japan

Tel +8I 738223256

Fax +81738222126

Email minakata.yoshiaki.qy@mail.hosp.go.jp
Background: Patients with COPD are less physically active. This post hoc analysis of a randomized, double-blind, active-controlled, crossover trial assessed the efficacy of oncedaily tiotropium/olodaterol combination therapy versus tiotropium monotherapy in Japanese patients with COPD.

Patients and methods: Patients were provided with a three-axis accelerometer to measure sedentary and active behavior defined as 1.0-1.5 metabolic equivalents (METs), $\geq 2.0$ METs, and $\geq 3.0$ METs, respectively. Of the 182 patients enrolled, 131 satisfied the conditions for the present analysis and were randomized to tiotropium monotherapy $(n=62)$ or tiotropium/ olodaterol combination therapy ( $n=69)$.

Results: Tiotropium/olodaterol combination therapy significantly reduced the duration of $1.0-1.5$ MET activity by 8.64 mins $(p=0.040)$ and significantly increased the duration of $\geq 2.0$ MET and $\geq 3.0$ MET activity by $6.51 \mathrm{mins}(p=0.017)$ and $2.60 \mathrm{mins}(p=0.008)$, respectively, compared with tiotropium alone. Subgroup analyses showed that better lung function, milder dyspnea, and higher levels of physical activity at baseline were associated with reduced sedentary time and increased duration of physical activity.

Conclusion: Tiotropium/olodaterol combination therapy significantly reduced sedentary time and improved physical activity compared with tiotropium monotherapy. This trial was registered in ClinicalTrials.gov (NCT02629965).

Keywords: COPD, Japanese, physical activity, sedentary behavior

\section{Introduction}

Physical activity and sedentary behavior both contribute to health outcomes, such that high mortality rates are observed in people who have low levels of physical activity and high sedentary times. ${ }^{1-3}$ There has been increasing recognition of the interrelationship between sitting time and physical activity, such that the 2018 Physical Activity Guidelines for Americans recommend that adults, and in particular older adults, "move more and sit less throughout the day.", Despite this, the effect of reducing sedentary time on health outcomes has not been fully investigated.

Sedentary behavior is defined as energy expenditure of $\leq 1.5$ metabolic equivalents (METs) while awake and in a sitting or reclining posture. ${ }^{5,6}$ People have a better health profile when they have less sedentary time. ${ }^{7}$ For example, increased sedentary time correlates with cardiac event risk and mortality, while less time spent sedentary is associated with higher levels of high-density lipoprotein 
cholesterol. ${ }^{8,9}$ Additionally, people with diabetes mellitus who have an increased number of breaks in their sedentary time have beneficial reductions in their waist circumferences and plasma glucose levels. ${ }^{10}$

Patients with COPD are markedly inactive because of airflow limitation. ${ }^{11}$ When people with COPD engage in activity, it is characterized by shortness of breath because of lung hyperinflation. ${ }^{12-14}$ However, in patients with COPD, the risk of death increases not only because of a reduced level of physical activity, but also because of an increased amount of sedentary time. It has previously been shown that patients with COPD have less standing time and prolonged sedentary time. ${ }^{11}$ Further, a recently published study showed that increased sedentary time is associated with a higher risk of death independent of physical activity among patients with COPD. ${ }^{15,16}$ Therefore, it is important to reduce sedentary behavior and increase physical activity in patients with COPD, as research shows that increasing low-intensity, rather than high-intensity, activities reduces the risk of hospitalization for these patients. $^{17}$

There are many factors that can affect the physical activity of patients with COPD, including comorbidities, physiological factors, and psychological factors. ${ }^{18}$ Currently, drug intervention trials assess patients with COPD based on patients' physical activity levels rather than sedentary behavior. This is primarily because a physical activity assessment is considered to be more objective and reliable than a questionnaire. ${ }^{19}$ However, physical activity data from an accelerometer require several variables to be prespecified to ensure high levels of reproducibility and sensitivity. This includes prespecification of observation intervals and a minimum number of days to obtain data, as well as exclusion of 1) non wear time, 2) periods when device malfunction interrupts recording of data, 3) periods when external factors such as bad weather prevent activity, and 4) sleeping time, especially for the evaluation of sedentary time.

It is now known that even if people are physically active, there are serious metabolic consequences associated with prolonged sedentary behavior. ${ }^{20-22}$ Therefore, targeting sedentary behavior in patients with COPD is an important consideration when evaluating how drug interventions work. Tiotropium is a widely used maintenance treatment for COPD. The VESUTO ${ }^{\circledR}$ study was designed to investigate the efficacy of a fixed dose of tiotropium in combination with olodaterol versus tiotropium monotherapy by assessing lung hyperinflation and exercise capacity in Japanese patients with COPD. ${ }^{23,24}$ To our knowledge, there are no reports presently available that describe bronchodilator use with reductions in sedentary duration.

Using the activity data of patients enrolled in the VESUTO study, we performed a post hoc analysis to investigate whether tiotropium/olodaterol combination therapy reduces sedentary time and increases activity levels compared with tiotropium monotherapy. Additionally, we investigated factors associated with reduced sedentary time and increased activity levels.

\section{Patients and methods}

\section{Patients}

The inclusion and exclusion criteria are described in full in the primary report. ${ }^{24}$ In brief, patients were included if they were aged $\geq 40$ years, diagnosed with COPD, and had a GOLD grade II-IV. Exclusion criteria included the presence of current documented bronchial asthma or a clinically significant abnormality in hematology, blood chemistry, or urinalysis parameters.

Institutional review boards at each participating site approved the study (see Table S1), and all patients provided written informed consent. The study was conducted in accordance with the International Conference on Harmonisation Guideline for Good Clinical Practice, the Declaration of Helsinki, the Japanese Good Clinical Practice regulations (Ministry of Health and Welfare Ordinance No. 28, March 27, 1997) and all relevant local regulatory, legal, and ethical requirements.

\section{Study design and treatment}

This was a post hoc analysis of the VESUTO study, where tiotropium/olodaterol combination therapy was compared with tiotropium monotherapy for its ability to improve inspiratory capacity (IC) and physical activity levels in patients with COPD. ${ }^{24}$ The VESUTO study was a multicenter, randomized, double-blind, active-controlled, twoway crossover trial as described previously. ${ }^{23}$ All patients received long-acting muscarinic antagonist (LAMA) or long-acting $\beta_{2}$-agonist (LABA) monotherapy for at least 5 weeks before randomization. After randomization, patients received once-daily tiotropium/olodaterol $5 / 5 \mu \mathrm{g}$ inhalation solution $(2.5 / 2.5 \mu \mathrm{g}$ per actuation) for 6 weeks, followed by tiotropium $5 \mu \mathrm{g}$ inhalation solution $(2.5 \mu \mathrm{g}$ per actuation) for 6 weeks, or vice versa. All inhalation solutions were administered via a RESPIMAT $^{\circledR}$ inhaler (Boehringer Ingelheim, Ingelheim, Germany). 


\section{Analysis of effects on physical activity durations}

During the VESUTO study, patients were provided with a three-axis accelerometer (Active style PRO HJA-750C, HJA-750C; OMRON, Kyoto, Japan) 2 weeks before the end of the 6-week study period to measure physical activity. Patients were asked to wear the accelerometer on their waist, all day, except when bathing or engaging in waterbased activities. Patients were not able to view data on the accelerometer screen. As previously defined, periods of sedentary time were categorized as an energy expenditure of 1.0-1.5 METs, whereas periods of physical activity performed at more than light (ie, light, moderate, or vigorous) and more than moderate (ie, moderate or vigorous) intensities were categorized as $\geq 2.0$ METs and $\geq 3.0$ METs, respectively. ${ }^{6,18,25}$

The duration of each MET category was calculated using raw data obtained from each patient. To enhance the sensitivity of these assessments and because sleeping time was not collected in all patients, data were collected from 8 AM to 9 PM to include the time when patients were awake and exclude the time spent sleeping, in keeping with a previous report. ${ }^{11}$ Furthermore, to obtain more reproducible data, and as in a previous study that assessed physical activity levels in patients with COPD,${ }^{19}$ activity data were excluded if the measurement device was worn for $<10 \mathrm{hrs}$ per day, and on rainy days, which have been shown to deter outdoor activity. ${ }^{19,26,27}$ Finally, at least 3 valid days were required (ie, days with $\geq 10$ hrs' wearing time and non rainy days). Wearing time was defined as periods with $>1.0$ MET. Rainy days were excluded based on patients' diaries. Therefore, activity data were excluded if there were fewer than 3 valid days during the study period. ${ }^{19}$

\section{Subgroup analyses}

The outcome variable was the mean difference between treatments (ie, tiotropium/olodaterol relative to tiotropium) in the change from baseline of the duration of each MET category. Improvement was defined as a greater decrease from baseline in the duration of 1.0-1.5 METs, or a greater increase from baseline in the duration of $\geq 2.0$ METs or $\geq 3.0$ METs, with tiotropium/olodaterol than with tiotropium. Subgroup analyses were performed to assess whether there were any differences in improvements in the duration of each MET category according to baseline characteristics, such as age; body mass index (BMI); lung function ( $\mathrm{FEV}_{1}$, IC, FVC); GOLD grade; mMRC) score; St George's Respiratory Questionnaire (SGRQ) total score, each domain activity, impact, and symptom score; and baseline duration of each MET category (1.0-1.5 METs, $\geq 2.0$ METs, and $\geq 3.0$ METs). Furthermore, we investigated the relationship between improvements in lung function and improvements in the duration of each MET category.

Additionally, the data of patients with $\mathrm{FEV}_{1}$ response $\left(\mathrm{FEV}_{1}\right.$ improvement $\geq 100 \mathrm{~mL}$ ) and those without $\mathrm{FEV}_{1}$ response $\left(\mathrm{FEV}_{1}\right.$ improvement $\left.<100 \mathrm{~mL}\right)$ were analyzed in terms of improvement in the duration of each MET category.

\section{Statistical methods}

The sample size calculation and preplanned analytical populations are described in the design paper. ${ }^{23}$ Statistical analyses to evaluate treatment effect were conducted using a mixed-effects model repeated measures (SAS/STAT ${ }^{\circledR}$ 13.1 MIXED procedure; SAS Institute Inc., Cary, NC, USA) approach with treatment and period as categorical fixed effects, study baseline (Visit 2) as a covariate, and patient as a random effect. Univariable and multivariable linear regression analyses were performed to explore the baseline factors associated with treatment response. As an appropriate clinical model regarding the relationship between baseline factors and improvement of physical activity is lacking, we included baseline factors, except for highly correlated factors such as those of lung function, in the multivariable regression model as explanatory variables. Factors were included as continuous variables, except for age $(<65,65-75$, or $\geq 75$ years, as per a previous report $\left.{ }^{28}\right)$, BMI $(<18.5,18.5-25$, or $\geq 25 \mathrm{~kg} / \mathrm{m}^{2}$ ), GOLD grade (II or III/IV), and mMRC score ( 1 or $\geq 2$ ). In addition, responder rate based on the duration of each MET category was calculated between groups with and without differences $\geq 100 \mathrm{~mL}$ in $\mathrm{FEV}_{1}$ between tiotropium/olodaterol and tiotropium alone. Differences between groups were judged to be statistically significant at $p<0.05$. However, as this is a post hoc analysis, the $p$ values reported should be considered nominal.

\section{Results \\ Patients}

The disposition of patients is shown in Figure 1. Of the 182 patients enrolled, 52 had fewer than 3 valid days and were excluded, resulting in 131 who satisfied the conditions for the present analysis. Two patients withdrew 


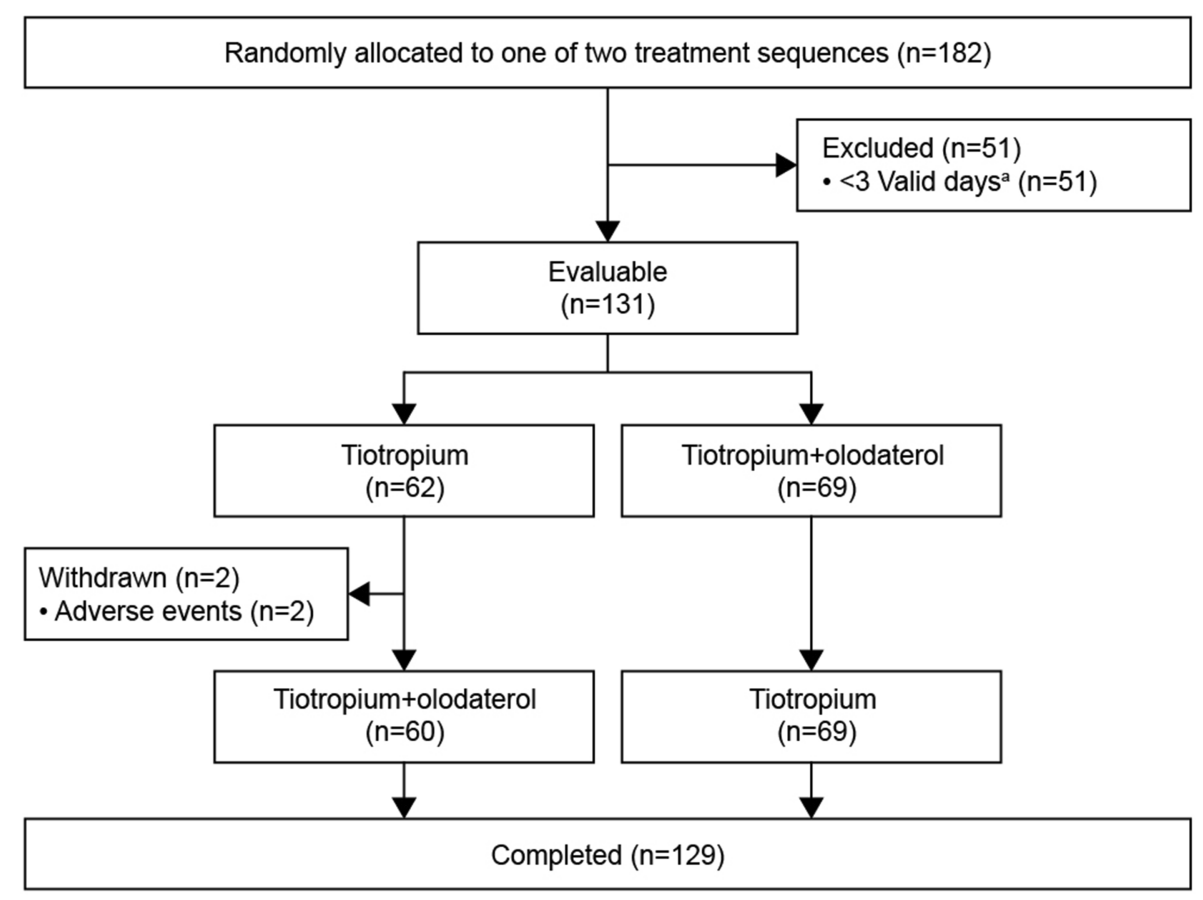

Figure I Patient disposition.

Note: 'Reasons for valid days included days with $\geq 10$ hrs' wearing time and non-rainy days.

informed consent after experiencing adverse events (unexpected worsening of the disease under study in both cases), while the remaining 129 patients completed the study. Baseline demographics and clinical characteristics are shown in Table 1.

For tiotropium/olodaterol combination therapy and tiotropium monotherapy, the mean $(\mathrm{SD})$ total wear time between 8 AM and 9 PM was 665.6 (51.2) mins and 668.4 (52.8) mins, respectively. In addition, the mean (SD) number of valid days was 11.23 (3.14) and 11.47 (2.89); the mean (SD) number of rainy days was 1.24 (2.09) and 1.12 (1.88); and the mean number of days with less than $10 \mathrm{hrs}$ ' wear time was $1.46(2.43)$ and 1.35 (2.21), respectively.

\section{Outcomes of analysis on physical activity durations}

Tiotropium/olodaterol combination therapy significantly reduced the duration of 1.0-1.5 METs by 8.64 mins more than with tiotropium monotherapy $(95 \% \mathrm{CI}-16.88$ to $-0.40 ; p=0.040$ ) (Figure 2A). In addition, tiotropium/ olodaterol combination therapy significantly increased the duration of $\geq 2.0$ METs by $6.51 \mathrm{mins}$ ( $95 \%$ CI 1.17 to $11.85 ; p=0.017)$ and $\geq 3.0$ METs by $2.60 \mathrm{mins}(95 \% \mathrm{CI}$ 0.70 to $4.49 ; p=0.008)$ more than with tiotropium monotherapy (Figure $2 \mathrm{~B}$ and $\mathrm{C}$ ).

\section{Subgroup analysis outcomes}

In the subgroup analysis of the relationship between patient characteristics and improvement in duration of each MET category, it was shown that, compared with tiotropium alone, tiotropium/olodaterol combination therapy significantly improved (reduced) the duration of 1.0 1.5 METs in subgroups with the following baseline characteristics: IC values greater than or equal to the median, FVC values greater than or equal to the median, age $\geq 75$ years, BMI $\geq 25 \mathrm{~kg} / \mathrm{m}^{2}$, SGRQ scores less than the median, and baseline duration of $\geq 3.0$ METs greater than or equal to the median (Figure 3A). Moreover, improvements in the duration of $\geq 2.0$ METs (Figure $3 \mathrm{~B}$ ) and the duration of $\geq 3.0$ METs (Figure 3C) tended to be greater with tiotropium/olodaterol than with tiotropium in patients aged $\geq 75$ years (significant for duration of $\geq 2.0$ METs only); in patients with BMI $\geq 25 \mathrm{~kg} / \mathrm{m}^{2}$ (significant for duration of 23.0 METs only); in those with the baseline lung function parameters IC, $\mathrm{FEV}_{1}$, and $\mathrm{FVC}$ values greater than or equal to the median; in those with GOLD grade II, $\mathrm{mMRC}=1$, and SGRQ scores less than the median value; and in those with baseline duration of 1.0-1.5 METs less than the median, baseline duration of $\geq 2.0$ METs greater than or equal to the median, and baseline duration of $\geq 3.0$ METs greater than or equal to the median. Similar 
Table I Patient demographics and baseline disease characteristics $(n=|3|)$

\begin{tabular}{|c|c|}
\hline Characteristic & Value \\
\hline Mean age, years (SD) & $71.6(6.6)$ \\
\hline Sex, male (\%) & $112(85.5)$ \\
\hline Mean body mass index, $\mathrm{kg} / \mathrm{m}^{2}(\mathrm{SD})$ & $21.7(4.0)$ \\
\hline Mean duration of COPD, years (SD) & $5.5(4.6)$ \\
\hline $\begin{array}{l}\text { Smoker status, n (\%) } \\
\text { Current } \\
\text { Ex-smoker }\end{array}$ & $\begin{array}{l}22(16.8) \\
109(83.2)\end{array}$ \\
\hline $\begin{array}{l}\text { Pulmonary function data (post bronchodilator), mean } \\
\text { (SD) } \\
\text { IC (L) } \\
\text { FEV । (L) } \\
\text { FEV , (\% predicted) } \\
\text { FVC (L) } \\
\text { FEV / /FVC (\%), mean (SD) }\end{array}$ & $\begin{array}{l}1.8 I(0.52) \\
1.22(0.4 I) \\
52.57(I 5.00) \\
2.96(0.7 I) \\
41.70(10.74)\end{array}$ \\
\hline $\begin{array}{l}\text { FEV , category, } \mathrm{n}(\%) \\
\text { GOLD grade II }(50 \% \text { to }<80 \%) \\
\text { GOLD grade III }(30 \% \text { to }<50 \%) \\
\text { GOLD grade IV }(<30 \%)\end{array}$ & $\begin{array}{l}73(55.7) \\
46(35.1) \\
12(9.2)\end{array}$ \\
\hline mMRC dyspnea score, mean (SD) & $1.9(0.8)$ \\
\hline $\begin{array}{l}\text { Mean daily physical activity duration (mins), mean } \\
(\mathrm{SD})^{\mathrm{a}} \\
\text { Duration of } 1.0-1.5 \mathrm{METs} \\
\text { Duration of } \geq 2.0 \mathrm{METs} \\
\text { Duration of } \geq 3.0 \mathrm{METs}\end{array}$ & $\begin{array}{l}408.4(90.0) \\
177.3(64.4) \\
44.2(24.7)\end{array}$ \\
\hline
\end{tabular}

Note: ${ }^{a}$ Measured over 14 days prior to baseline.

Abbreviations: IC, inspiratory capacity; METs, metabolic equivalents.

tendencies were also observed when the percent change from baseline in the duration of each MET category was examined (Figure S1).

Univariable and multivariable analyses were conducted to investigate associations of baseline age, BMI, IC, $\mathrm{FEV}_{1}$, FVC, GOLD, mMRC, SGRQ, and duration of each MET category with patient outcomes. There was an association between baseline SGRQ total score and SGRQ activity domain and an improvement in duration of 1.0-1.5 METs in the univariable analysis; similar results were observed for the SGRQ activity domain in the multivariable analysis (Table 2A). The univariable analysis showed that $\mathrm{FEV}_{1}, \mathrm{FVC}$, and SGRQ total score, activity domain, and impact domain were associated with improvements in the duration of $\geq 2.0$ METs. However, statistical significance was not observed in the multivariable analysis (Table 2B). Regarding the duration of $\geq 3.0$ METs, the univariable analysis showed that $\mathrm{FEV}_{1}, \mathrm{FVC}$, and SGRQ activity domains were associated with improvements, and the multivariable analysis showed that $\mathrm{BMI}, \mathrm{FEV}_{1}$, and SGRQ activity domains were associated with improvements in this activity level (Table 2C).

We then investigated whether improvements in lung function parameters achieved during treatment were associated with improved duration of each MET category. Patients with an improvement in $\mathrm{FEV}_{1}$ that was greater than or equal to the median $\mathrm{FEV}_{1}$ after treatment showed reductions in the duration of 1.0-1.5 METs (Figure 4A; -12.65 mins $[95 \% \mathrm{CI}-24.10$ to -1.21$]$ ) and increases in the durations of $\geq 2.0$ METs (Figure 4B; 8.92 mins [95\% CI 1.13 to 16.71$]$ ) and $\geq 3.0$ METs (Figure 4C: $2.93 \mathrm{mins}$ [95\% CI 0.11 to 5.76]). Similar tendencies were observed when the percent change from baseline duration of each MET category was examined (Figure S2).

Additionally, it was shown that patients who had $\mathrm{FEV}_{1}$ improvements $\geq 100 \mathrm{~mL}\left(\mathrm{FEV}_{1}\right.$ responders) tended to experience greater improvements in the duration of each MET category than $\mathrm{FEV}_{1}$ non responders $\left(\Delta \mathrm{FEV}_{1}<100\right.$ $\mathrm{mL}$ ) (Figure S3).

\section{Discussion}

The VESUTO study initially showed that tiotropium/olodaterol combination therapy reduced hyperinflation, potentially improved exercise capacity, and resulted in mild-to-moderate increases in the duration of active behavior, compared with tiotropium monotherapy. ${ }^{24}$ This post hoc analysis showed that tiotropium/olodaterol combination therapy statistically significantly reduced the duration of 1.0-1.5 METs (sedentary time) by $8.64 \mathrm{mins}$ and increased the durations of $\geq 2.0$ METs and $\geq 3.0$ MET physical activity by 6.51 mins and 2.60 mins, respectively. To our knowledge, this is the first study to provide evidence of a significant reduction in sedentary time in patients with COPD who are administered LAMA/LABA compared to LAMA alone, although the clinical meaning of this change is unclear. These findings may be important because sedentary time has been shown to increase the risk of mortality independent of the duration of active behavior in patients with COPD. ${ }^{15,16}$ Moreover, increasing the duration of low-intensity activity, rather than high-intensity activity, contributes to a lower risk of hospitalization in patients with COPD. ${ }^{17}$

In this study, the subgroup analyses showed that compared with tiotropium alone, tiotropium/olodaterol combination therapy decreased sedentary time and increased 


\section{A Average daily duration 1.0-1.5 METs}

Adj. mean difference: -8.64 minutes ( $95 \% \mathrm{Cl}-16.88$ to $-0.40 ; P=0.040$ )

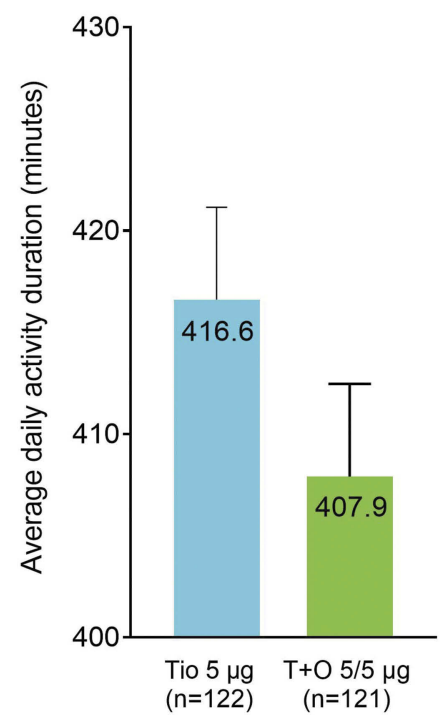

\section{B Average daily duration} $\geq 2.0$ METs

Adj. mean difference: 6.51 minutes (95\% Cl 1.17 to $11.85 ; P=0.017)$

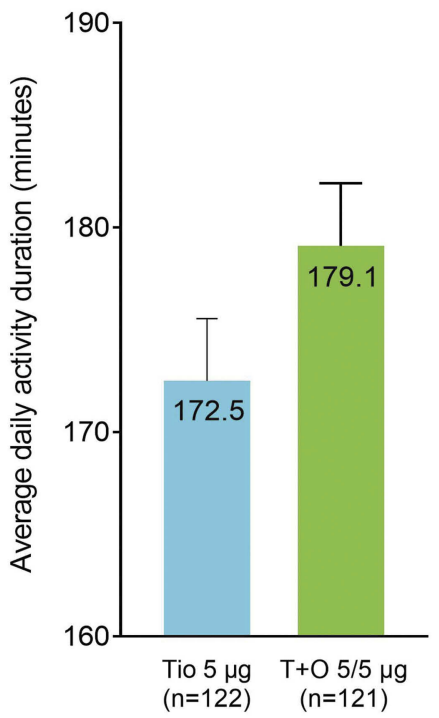

\section{Average daily duration $\geq 3.0$ METs}

Adj. mean difference: 2.60 minutes (95\% $\mathrm{Cl} 0.70$ to $4.49 ; P=0.008)$

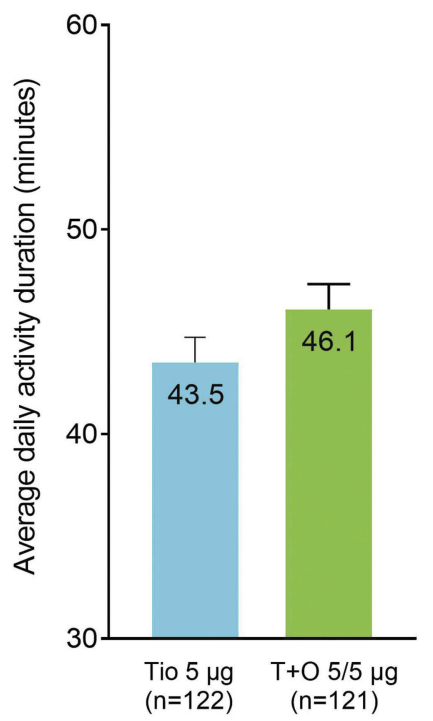

Figure 2 Activity durations for 1.0-1.5 METs (A), $\geq 2.0$ METs (B), and $\geq 3.0$ METs (C).

Notes: Error bars represent SEs.

Abbreviations: Adj., adjusted; METs, metabolic equivalents; Tio, tiotropium; T+O, tiotropium/olodaterol.

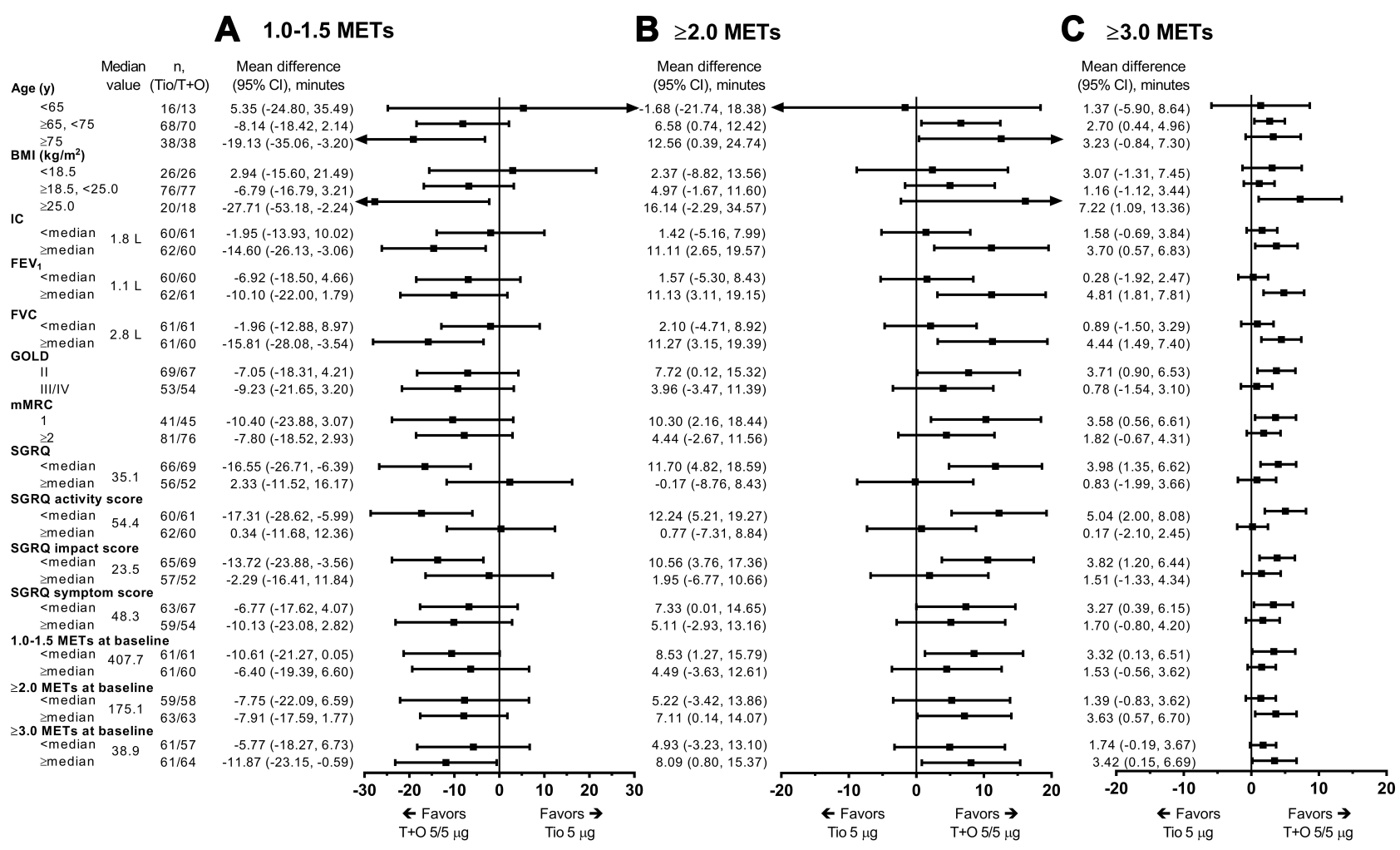

Figure 3 The effect of tiotropium/olodaterol combination therapy versus tiotropium monotherapy in time spent on 1.0-1.5 METs (A), $\geq 2.0$ METs (B), and $\geq 3.0$ METs (C) activity levels (change from baseline) by subgroups defined by baseline factors.

Abbreviations: BMI, body mass index; IC, inspiratory capacity; METs, metabolic equivalents; SGRQ, St George's Respiratory Questionnaire; Tio, tiotropium; T+O, tiotropium/olodaterol. 


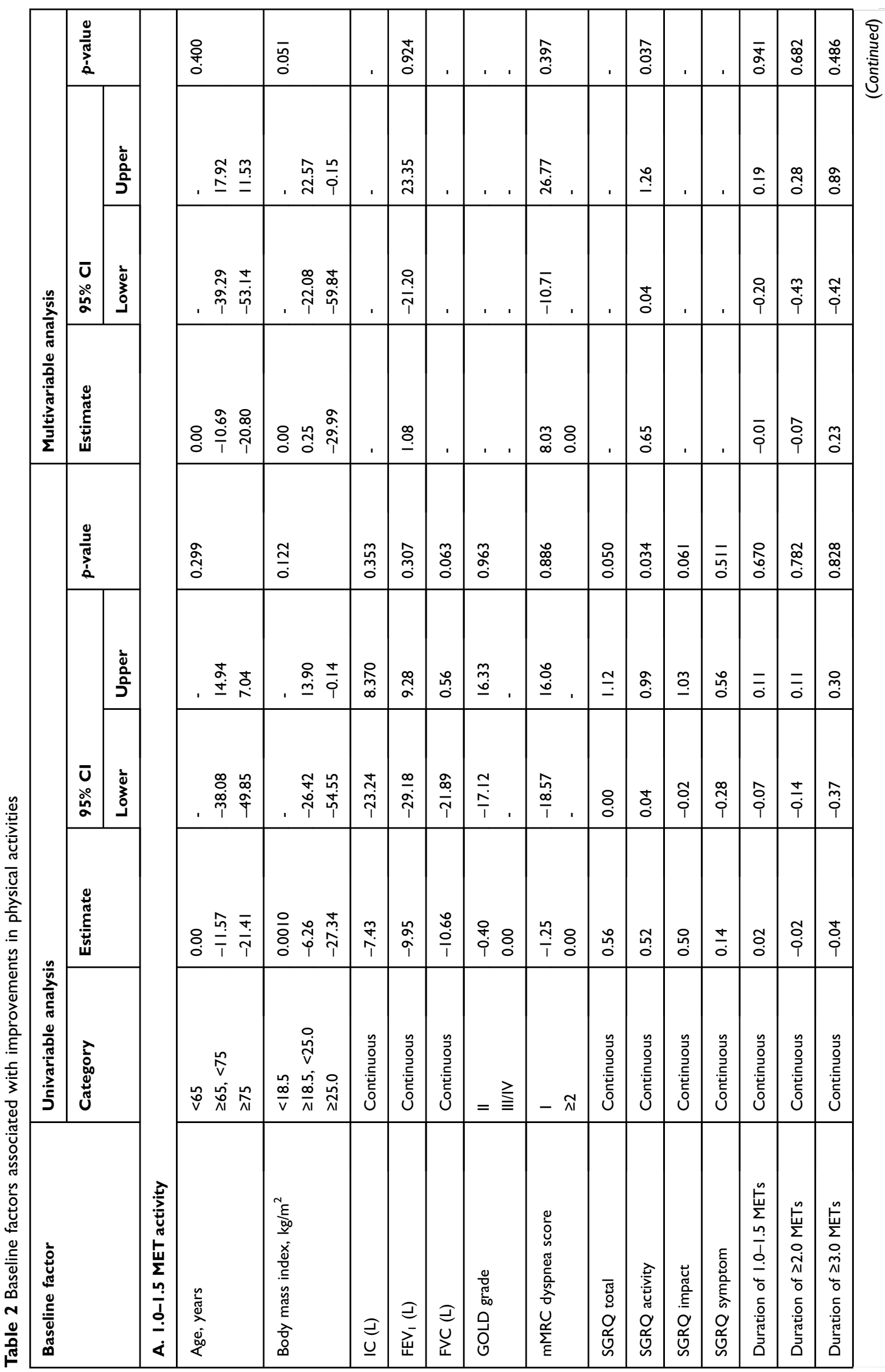




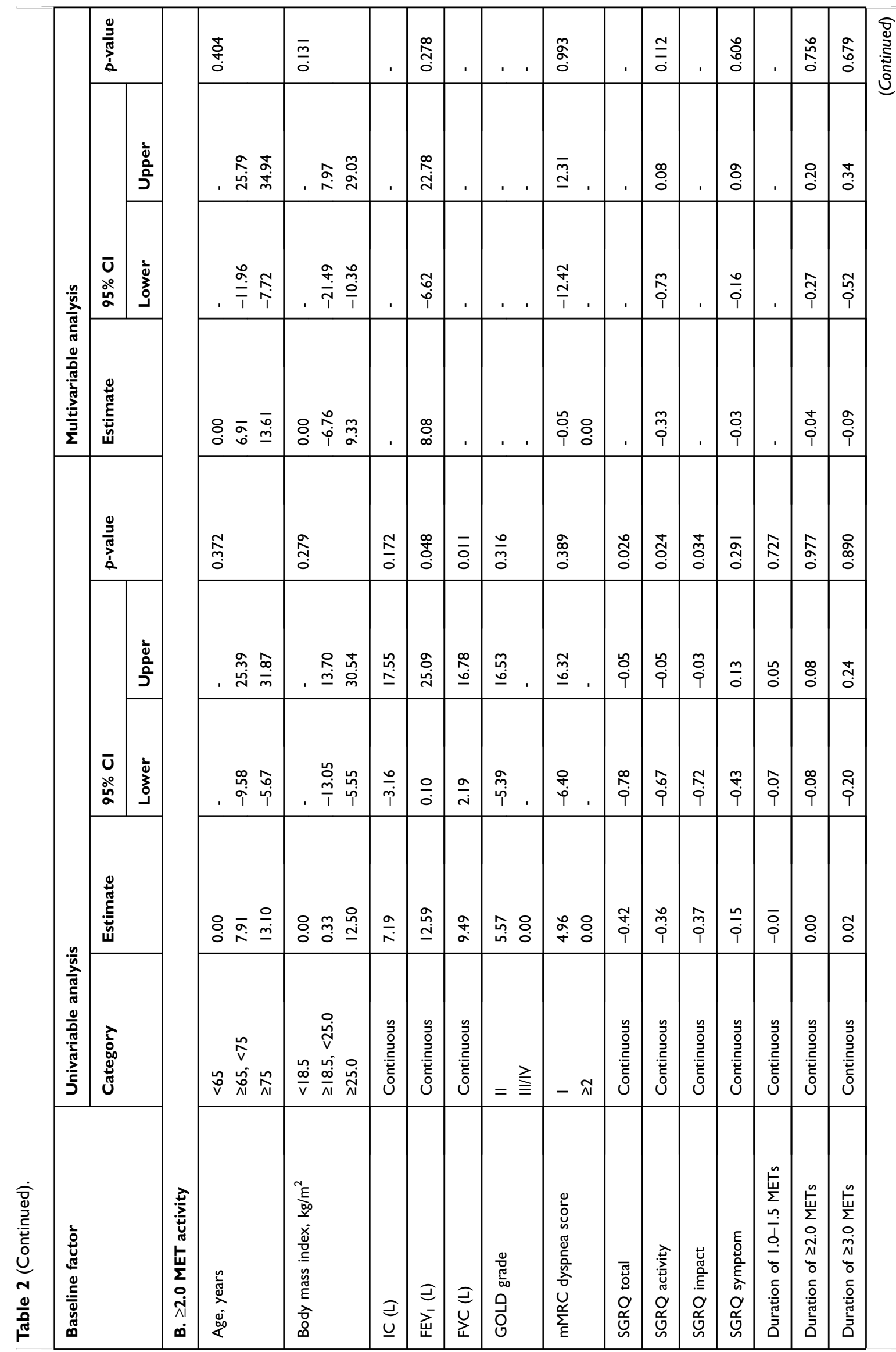




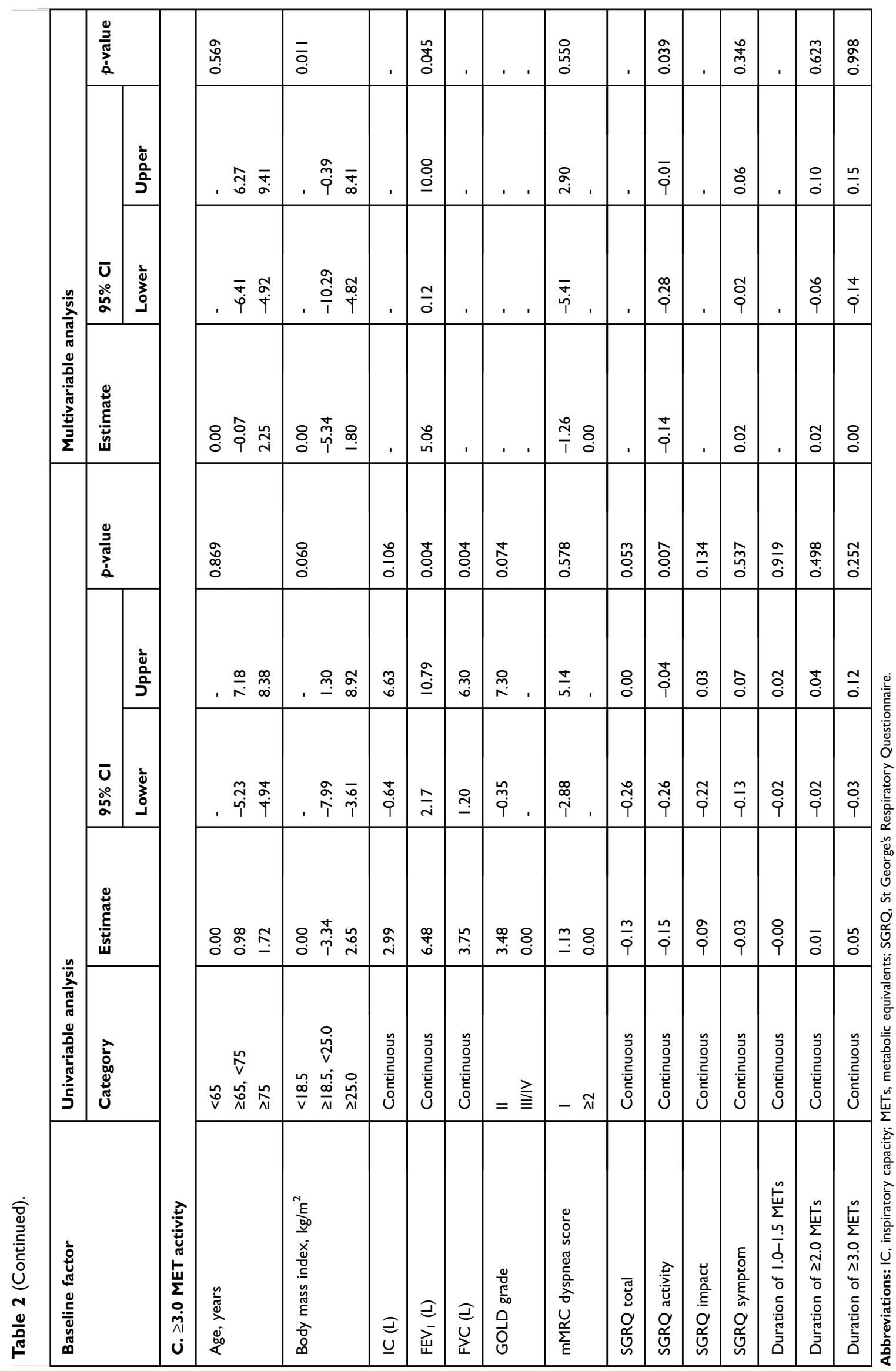



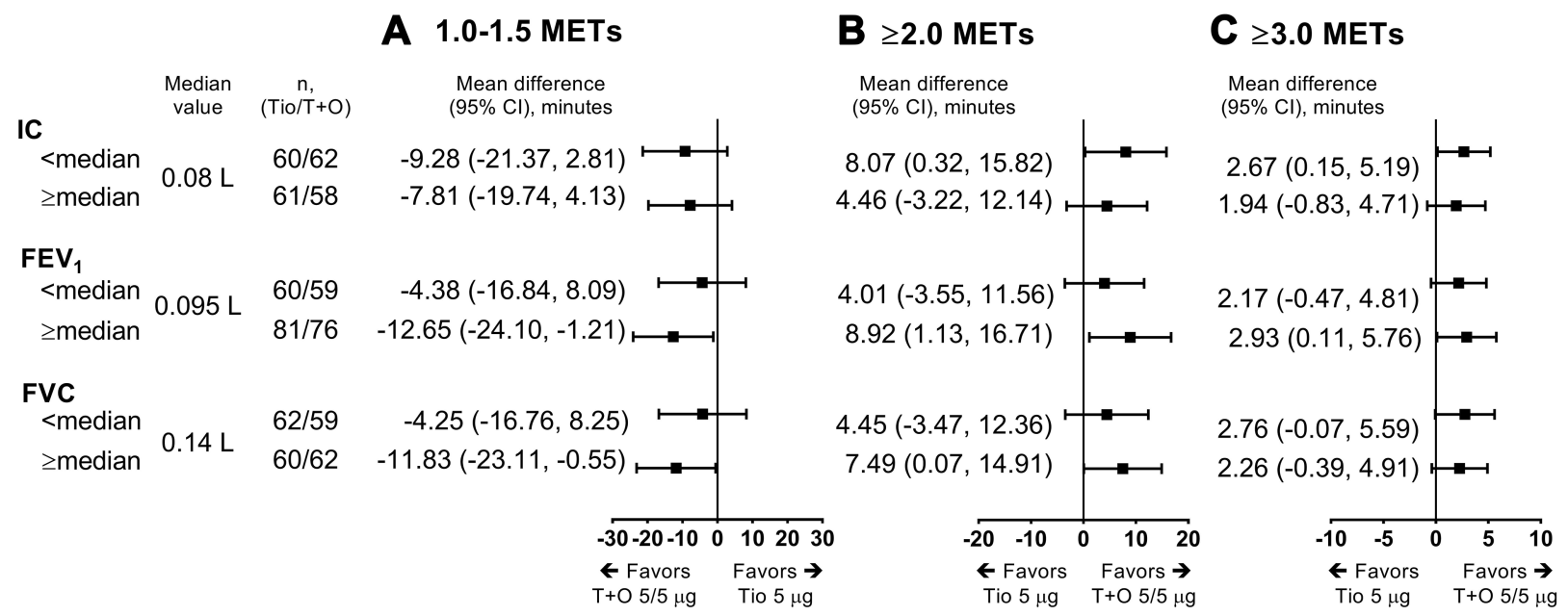

Figure 4 The relationship between improvements in lung function during treatment and duration of I.0-I.5 MET (A), $\geq 2.0$ MET (B), and $\geq 3.0$ MET (C) activity levels (change from baseline).

Abbreviations: IC, inspiratory capacity; METs, metabolic equivalents; SGRQ, St George's Respiratory Questionnaire; Tio, tiotropium; T+O, tiotropium/olodaterol.

physical activity in patients with better baseline lung function, milder dyspnea, and higher levels of physical activity at baseline, and in patients who were older and overweight. In addition, sedentary time was shorter and the duration of physical activity was longer in subjects aged $\geq 75$ years, which may have been due to patients aged $\geq 75$ years having higher baseline activity levels. This is supported by findings from the Japan National Health and Nutrition Survey from 2016, which showed that selfreported regular exercise habits were higher in patients aged $\geq 70$ years than in subjects aged between 60 and 70 years. ${ }^{29}$ Overall, our findings suggest that patients with COPD and milder airflow limitations, milder symptoms, and a higher physical activity level at baseline may show greater improvements in physical activity with tiotropium/ olodaterol combination therapy compared with tiotropium monotherapy. Although further trials are required to determine the effect of these factors, these findings are consistent with previous findings and suggest that early treatment with tiotropium/olodaterol combination therapy in patients with less severe disease could contribute to enhanced physical activity levels. ${ }^{30,31}$

The multivariable regression analysis showed no statistically significant associations between baseline characteristics and sedentary improvement. However, baseline $\mathrm{FEV}_{1}$ was associated with improvements in $\geq 3.0$ METs. This suggests that lifestyle and socio environmental factors, rather than baseline lung function, influence sedentary time, whereas activity $\geq 3.0$ METs (moderate-to-vigorous intensity) is more influenced by lung function. This is consistent with a previous observational study in which a change in the high intensity of physical activity after bronchodilator use correlated with baseline lung function. ${ }^{30}$

Subsequently, we investigated whether improvements in lung function after 6 weeks of treatment were associated with improvements in physical activity. There was a tendency for decreased sedentary times and increased physical activity durations in patients who had greater improvements in lung function, such as $\mathrm{FEV}_{1}$. This suggests that the improved airflow limitation observed with tiotropium/olodaterol combination therapy may contribute to improvements in patients' physical activity. ${ }^{32,33}$ To further support this point, we also observed that there was a tendency for improved physical activity among patients who showed improvements of $>100 \mathrm{~mL}$ in $\mathrm{FEV}_{1}$.

When assessing physical activity levels, it is important to extract only valid data to ensure enhanced reliability/ sensitivity. In particular, sleeping time and non wear time have a greater effect on the evaluation of sedentary time than on the evaluation of active behavior. Therefore, to ensure valid data for assessment of sedentary time, we used stricter criteria than in our previous report. Specifically, we aimed to extract data when patients were awake (ie, between 8 AM and 9 PM), as the exclusion of sleeping time is critical for accurately evaluating sedentary time. We also excluded days when patients wore the activity measurement device $<10 \mathrm{hrs}$, and when it was raining (which can affect physical activity). Importantly, we included data only from patients who had $\geq 3$ valid days. ${ }^{34}$ 
It has been previously reported that seasons and possibly also the weather can significantly affect physical activity levels. ${ }^{35,36}$ Therefore, although we excluded data from rainy days, it is possible that seasonal differences in physical activity may have occurred during the VESUTO study, which enrolled patients throughout an entire year. ${ }^{24}$ Overall, the conditions used to define valid data were stricter than in our previous report.

We used the three-axis accelerometer HJA-750C in which 3 different algorithms were employed to evaluate sedentary, light-intensity, and moderate-intensity activity. ${ }^{37}$ This monitor is comparable with the already validated DynaPort Move Monitor (McRoberts, The Hague, The Netherlands) and the Actimaker (Panasonic, Osaka, Japan). ${ }^{34}$ Therefore, the HJA-750C model was considered to be an appropriate measure for analyzing both active and sedentary time in this study.

Although an increase of 1000 steps in daily walking can reduce the risk of hospitalization by $20 \%,{ }^{17}$ the findings from our study suggest that it is equally important to reduce time spent in inactive postures such as sitting. The American College of Sports Medicine recommends either $\geq 30$ mins of moderate aerobic exercise 5 days per week or $\geq 20$ mins of vigorous exercise 3 days per week ${ }^{38}$ and, although the 2018 Physical Activity Guidelines for Americans acknowledge the risks of excessive sedentary time, there are no quantitative guidelines currently available for sitting time or recommendations for sitting time durations throughout the day. ${ }^{4}$

Our findings showed that sedentary time decreased with tiotropium/olodaterol combination therapy. However, it remains unclear whether this indicates a clinically significant improvement with drug treatment and whether this improvement can contribute to better clinical outcomes. Therefore, further studies are required to determine the clinical relevance of improvements in sedentary time with tiotropium/olodaterol combination therapy. It is expected that, in addition to drug interventions, further reductions in sedentary time and improved levels of physical activity could be achieved with patient education, rehabilitation, and behavioral change programs. ${ }^{18}$

\section{Limitations}

This study is limited by the post hoc nature of the analyses of a study that was not designed to evaluate sedentary time, the use of exploratory analyses that were not adjusted for multiplicity, the relatively short duration of the study, and the inclusion of only Japanese patients with COPD, which limits the generalizability to other populations. In this study, patients were asked to wear their accelerometers all day for 14 days, and 51 of 182 patients were excluded from the analyses because they had fewer than 3 valid days (ie, $\geq 10$ hrs' wearing time and non rainy days). Guidelines for extracting data for the assessment of physical activity levels were not stipulated, and non wearing time and lying down resting periods are not clearly distinguishable, which is a limitation inherent in all activity monitors. Therefore, it is possible that patients may have slept within the data collection period of $8 \mathrm{AM}$ to $9 \mathrm{PM}$. In addition, lung function is not the only contributor to the physically inactive lifestyle of many individuals with COPD, and physical activity can be affected by many other factors including comorbidities, physiological factors, and psychological well-being. ${ }^{18}$ However, the crossover design of this study would, in part, control for any potential differences in these contributing factors between groups.

\section{Conclusion}

This post hoc analysis of the VESUTO study showed that tiotropium/olodaterol combination therapy reduced the sedentary time (1.0-1.5 METs) and improved the duration of more than light ( $\geq 2.0$ METs) and more than moderate ( $\geq 3.0$ METs) activity compared with tiotropium monotherapy. The limitations of this research should be taken into account when designing future studies.

\section{Abbreviations}

BMI, body mass index; IC, inspiratory capacity; METs, metabolic equivalents; SGRQ, St George's Respiratory Questionnaire.

\section{Data availability}

To ensure independent interpretation of clinical study results, Boehringer Ingelheim grants all external authors access to all relevant material, including participant-level clinical study data, and relevant material as needed by them to fulfill their role and obligations as authors under the ICMJE criteria. Furthermore, clinical study documents (eg, study report, study protocol, and statistical analysis plan) and participant clinical study data are available to be shared after publication of the primary manuscript in a peerreviewed journal and if regulatory activities are complete and other criteria met per the BI Policy on Transparency and Publication of Clinical Study Data: https://trials.boehrin ger-ingelheim.com/transparency_policy.html. Prior to providing access, documents will be examined, and, if 
necessary, redacted and the data will be de-identified, to protect the personal data of study participants and personnel, and to respect the boundaries of the informed consent of the study participants. Clinical Study Reports and Related Clinical Documents can be requested via this link: https:// trials.boehringer-ingelheim.com/trial_results/clinical_sub mission documents.html. All such requests will be governed by a Document Sharing Agreement. Bona fide, qualified scientific and medical researchers may request access to de-identified, analyzable participant clinical study data with corresponding documentation describing the structure and content of the datasets. Upon approval, and governed by a Data Sharing Agreement, data are shared in a secured data-access system for a limited period of 1 year, which may be extended upon request. Researchers should use https:// clinicalstudydatarequest.com to request access to study data.

\section{Acknowledgments}

We thank James Graham, PhD, of Edanz Medical Writing for providing medical writing support and Serina Stretton, PhD, CMPP of ProScribe - Envision Pharma Group for editorial assistance. Medical writing support and editorial assistance were funded by Nippon Boehringer Ingelheim. This work was supported by Nippon Boehringer Ingelheim Co., Ltd., Tokyo, Japan. Boehringer Ingelheim was involved in the study design, data collection, data analysis, and preparation of the manuscript. Some results of this study were previously presented as a poster at the European Respiratory Society 2018 International Congress (Paris, France, 15-19 September 2018).

\section{Author contributions}

YM, TM, JU, SN, TA, KH, and MI were involved in the study design and data analyses. TA conducted the statistical analysis. All authors contributed to data analysis, drafting or revising the article, gave final approval of the version to be published, and agree to be accountable for all aspects of the work

\section{Disclosure}

Y. Minakata reports non financial support from Nippon Boehringer Ingelheim, during the conduct of the study and personal fees from Nippon Boehringer Ingelheim, outside the submitted work. T. Motegi reports personal fees, non financial support from Nippon Boehringer Ingelheim, during the conduct of the study; personal fees from Nippon Boehringer
Ingelheim, Fukuda Life Tech and AstraZeneca, outside the submitted work. J. Ueki reports personal fees from Nippon Boehringer Ingelheim, Hoshi Iryo Sanki, Teijin Pharma and Novartis Pharma, during the conduct of the study. Y. Gon reports personal fees from Nippon Boehringer Ingelheim, during the conduct of the study and personal fees from Novartis Pharma, Nippon Boehringer Ingelheim, Astra Zeneca and Kyorin Pharma, outside the submitted work. S. Nakamura is an employee of Nippon Boehringer Ingelheim. T. Anzai reports compensation for statistical analysis services from Nippon Boehringer Ingelheim during the conduct of the study and outside the submitted work. K. Hirata reports non financial support from Nippon Boehringer Ingelheim, during the conduct of the study and personal fees from Nippon Boehringer Ingelheim, outside the submitted work. M. Ichinose has received honoraria from AstraZeneca, Nippon Boehringer Ingelheim, and Novartis Pharma. The authors report no other conflicts of interest in this work.

\section{References}

1. Inoue M, Iso H, Yamamoto S, et al. Daily total physical activity level and premature death in men and women: results from a large-scale population-based cohort study in Japan (JPHC study). Ann Epidemiol. 2008;18:522-530. doi:10.1016/j.annepidem.2008.03.008

2. van der Ploeg H, Chey T, Korda RJ, Banks E, Bauman A. Sitting time and all-cause mortality risk in 222497 Australian adults. Arch Intern Med. 2012;172:494-500. doi:10.1001/archinternmed.2011.2174

3. Biswas A, Oh PI, Faulkner GE, et al. Sedentary time and its association with risk for disease incidence, mortality, and hospitalization in adults: a systematic review and meta-analysis. Ann Intern Med. 2015;162:123-132. doi:10.7326/M14-1651

4. Piercy KL, Troiano RP, Ballard RM, et al. The physical activity guidelines for Americans. JAMA. 2018;320:2020-2028.

5. Ainsworth BE, Haskell WL, Whitt MC, et al. Compendium of physical activities: an update of activity codes and MET intensities. Med Sci Sports Exerc. 2000;32(9 Suppl):S498-S504.

6. Tremblay MS, Aubert S, Barnes JD, et al. Sedentary Behavior Research Network (SBRN) - terminology consensus project process and outcome. Int J Behav Nutr Phys Act. 2017;14:75.

7. Owen N, Healy GN, Matthews CE, Dunstan DW. Too much sitting: the population health science of sedentary behavior. Exerc Sport Sci Rev. 2010;38:105-113.

8. Bakrania K, Edwardson CL, Bodicoat DH, et al. Associations of mutually exclusive categories of physical activity and sedentary time with markers of cardiometabolic health in English adults: a cross-sectional analysis of the Health Survey for England. BMC Public Health. 2016;16:25.

9. Young DR, Hivert MF, Alhassan S, et al. Sedentary behavior and cardiovascular morbidity and mortality: a science advisory from the American Heart Association. Circulation. 2016;134:e262-e279.

10. Healy GN, Dunstan DW, Salmon J, et al. Breaks in sedentary time: beneficial associations with metabolic risk. Diabetes Care. 2008;31:661-666. doi:10.2337/dc07-1868

11. Pitta F, Troosters T, Spruit MA, Probst VS, Decramer M, Gosselink R. Characteristics of physical activities in daily life in chronic obstructive pulmonary disease. Am J Respir Crit Care Med. 2005;171:972-977. doi:10.1164/rccm.200407-855OC 
12. Deesomchok A, Webb KA, Forkert L, et al. Lung hyperinflation and its reversibility in patients with airway obstruction of varying severity. COPD. 2010;7:428-437. doi:10.3109/15412555.2010.528087

13. O'Donnell DE, Revill SM, Webb KA. Dynamic hyperinflation and exercise intolerance in chronic obstructive pulmonary disease. Am J Respir Crit Care Med. 2001;164:770-777. doi:10.1164/ajrccm. 164.5.2012122

14. O'Donnell DE, Laveneziana P. Dyspnea and activity limitation in COPD: mechanical factors. COPD. 2007;4:225-236. doi:10.1080/ 15412550701480455

15. McKeough Z, Cheng SWM, Alison J, Jenkins C, Hamer M, Stamatakis E. Low leisure-based sitting time and being physically active were associated with reduced odds of death and diabetes in people with chronic obstructive pulmonary disease: a cohort study. $J$ Physiother. 2018;64:114-120. doi:10.1016/j.jphys.2018.02.007

16. Furlanetto KC, Donária L, Schneider LP, et al. Sedentary behavior is an independent predictor of mortality in subjects with COPD. Respir Care. 2017;62:579-587. doi:10.4187/respcare.05306

17. Donaire-Gonzalez D, Gimeno-Santos E, Balcells E, et al. Benefits of physical activity on COPD hospitalisation depend on intensity. Eur Respir J. 2015;46:1281-1289. doi:10.1183/13993003.01699-2014

18. Cavalheri V, Straker L, Gucciardi DF, Gardiner PA, Hill K. Changing physical activity and sedentary behaviour in people with COPD. Respirology. 2016;21:419-426. doi:10.1111/resp.12680

19. Byrom B, Rowe DA. Measuring free-living physical activity in COPD patients: deriving methodology standards for clinical trials through a review of research studies. Contemp Clin Trials. 2016;47:172-184. doi:10.1016/j.cct.2016.01.006

20. Hamilton MT, Hamilton DG, Zderic TW. Exercise physiology versus inactivity physiology: an essential concept for understanding lipoprotein lipase regulation. Exerc Sport Sci Rev. 2004;32:161-166. doi:10.1097/00003677-200410000-00007

21. Hamilton MT, Healy GN, Dunstan DW, Zderic TW, Owen N. Too little exercise and too much sitting: inactivity physiology and the need for new recommendations on sedentary behavior. Curr Cardiovasc Risk Rep. 2008;2:292-298. doi:10.1007/s12170-008-0054-8

22. Owen N, Baumann A, Brown W. Too much sitting: a novel and important predictor of chronic disease risk? $\mathrm{Br} J$ Sports Med. 2009;43:81-83. doi:10.1136/bjsm.2008.055269

23. Ichinose M, Minakata Y, Motegi T, et al. Study design of VESUTO ${ }^{\circledR}$ : efficacy of tiotropium/olodaterol on lung hyperinflation, exercise capacity, and physical activity in Japanese patients with chronic obstructive pulmonary disease. Adv Ther. 2017;34:1622-1635. doi:10.1007/s12325-017-0554-3

24. Ichinose M, Minakata Y, Motegi T, et al. Efficacy of tiotropium/ olodaterol on lung volume, exercise capacity, and physical activity. Int J COPD. 2018;13:1407-1419. doi:10.2147/COPD.S166023

25. Sedentary Behaviour Research Network. Letter to the editor: standardized use of the terms "sedentary" and "sedentary behaviours". Appl Physiol Nutr Metab. 2012;37:540-542. doi:10.1139/h2012-024
26. Watz H, Pitta F, Rochester CL, et al. An official European Respiratory Society statement on physical activity in COPD. Eur Respir J. 2014;44:1521-1537. doi:10.1183/09031936.00003814

27. Sugino A, Minakata Y, Kanda M, et al. Validation of a compact motion sensor for the measurement of physical activity in patients with chronic obstructive pulmonary disease. Respiration. 2012;83:300-307. doi:10.1159/000330046

28. Ferguson GT, Karpel JP, Clerisme-Beaty E, Grönke L, Voß F, Buhl R. Efficacy and safety of tiotropium + olodaterol maintenance treatment in patients with COPD in the TONADO ${ }^{\circledR}$ and OTEMTO ${ }^{\circledR}$ studies: a subgroup analysis by age. Int $J$ Chron Obstruct Pulmon Dis. 2016;11:2701-2710. doi:10.2147/COPD.S108758

29. Japanese Ministry of Health, Labour and Welfare. The National Health and Nutrition Survey. 2016. Available from: www.mhlw.go. jp/bunya/kenkou/kenkou_eiyou_chousa.html. Accessed November 23, 2018. Japanese.

30. Minakata Y, Morishita Y, Ichikawa T, et al. Effects of pharmacologic treatment based on airflow limitation and breathlessness on daily physical activity in patients with chronic obstructive pulmonary disease. Int J Chron Obstruct Pulmon Dis. 2015;10:1275-1282. doi:10.2147/COPD.S84134

31. Ferguson GT, Flezar M, Korn S, et al. Efficacy of tiotropium + olodaterol in patients with chronic obstructive pulmonary disease by initial disease severity and treatment intensity: a post hoc analysis. Adv Ther. 2015;32:523-536. doi:10.1007/s12325-015-0218-0

32. McCarthy B, Casey D, Devane D, Murphy K, Murphy E, Lacasse Y. Pulmonary rehabilitation for chronic obstructive pulmonary disease. Cochrane Database Syst Rev. 2015;2:CD003793.

33. Spruit MA, Pitta F, McAuley E, ZuWallack RL, Nici L. Pulmonary rehabilitation and physical activity in patients with chronic obstructive pulmonary disease. Am J Respir Crit Care Med. 2015;192:924933. doi:10.1164/rccm.201505-0929CI

34. Miyamoto S, Minakata Y, Azuma Y, et al. Verification of a motion sensor for evaluating physical activity in COPD patients. Can Respir J. 2018;2018:8343705.

35. Sewell L, Singh SJ, Williams JE, Morgan MD. Seasonal variations affect physical activity and pulmonary rehabilitation outcomes. $J$ Cardiopulm Rehabil Prev. 2010;30:329-333.

36. Donaldson GC, Goldring JJ, Wedzicha JA. Influence of season on exacerbation characteristics in patients with COPD. Chest. 2012;141:94-100.

37. Ohkawara K, Oshima Y, Hikihara Y, Ishikawa-Takata K, Tabata I, Tanaka S. Real-time estimation of daily physical activity intensity by a triaxial accelerometer and a gravity-removal classification algorithm. Br J Nutr. 2011;105:1681-1691.

38. Garber CE, Blissmer B, Deschenes MR, et al. Quantity and quality of exercise for developing and maintaining cardiorespiratory, musculoskeletal, and neuromotor fitness in apparently healthy adults: guidance for prescribing exercise. Med Sci Sports Exerc. 2011;43:1334-1359.
The International Journal of COPD is an international, peer-reviewed journal of therapeutics and pharmacology focusing on concise rapid reporting of clinical studies and reviews in COPD. Special focus is given to the pathophysiological processes underlying the disease, intervention programs, patient focused education, and self management protocols. This journal is indexed on PubMed Central, MedLine and CAS. The manuscript management system is completely online and includes a very quick and fair peer-review system, which is all easy to use. Visit http://www.dovepress.com/testimonials.php to read real quotes from published authors. 